\title{
Processing Verbs in German Idioms: Evidence Against the Configuration Hypothesis
}

\author{
Eva Smolka \\ Experimental and Biological Psychology \\ University of Marburg, Germany and Cognitive Neuroscience \\ and Psycholinguistics, University of La Laguna, Spain \\ Stefan Rabanus \\ Department of Germanic and Slavic Studies \\ University of Verona, Italy \\ Frank Rösler \\ Experimental and Biological Psychology \\ University of Marburg, Germany
}

\begin{abstract}
This study investigated whether verbs in figurative language activate different types of associations than do verbs in literal language. In a sentence-priming experiment, we compared sentences featuring verbs in idiomatic phrases with control sentences in which the same verbs were meant literally. Participants made lexical decisions about nouns that were associated with either the verb's literal meaning, with the figurative meaning of the phrase, or were unassociated nouns. Verbs in sentence-final position were highly predictable in both types of sentences and hence the phrasal meaning was rendered as figurative or literal before the sentence-final word. Our results showed that in literal sentences, the activation of literal associations was much stronger than that of figurative associations, whereas in idiomatic sentences, associations with the literal meaning of the verb were activated to the same degree as were associations with the figurative meaning. This contrasts with previous psycholinguistic research suggesting that literal associations should not be activated as soon as the phrase has been recognized as idiom. We argue that the literal verb meaning is essen-
\end{abstract}

Requests for reprints should be sent to Eva Smolka, Departmento de Psicología Cognitiva, Universidad de La Laguna, 38205 La Laguna, Tenerife, Spain. E-mail:esmolka@ull.es 
tial in both figurative and nonfigurative language and present a model of idiom recognition that integrates our findings.

\section{PROCESSING VERBS IN GERMAN IDIOMS: EVIDENCE AGAINST THE CONFIGURATION HYPOTHESIS}

One of the basic assumptions in semantics is the Composition Principle (Frege, 1923), according to which phrasal constructions can be semantically decomposed with respect to the literal meanings and syntactic structure of their constituents. There are, however, a large number of figurative expressions, such as the idiom "He blew off some steam" that seem to be anomalous with respect to the Composition Principle. Nevertheless, figurative expressions do not pose problems for the native speaker. Speakers use them frequently in everyday language, and are usually not even aware of their nonliteral nature (Cacciari \& Glucksberg, 1994; Gibbs, 1994). Yet, classical linguistics and literary theory, as well as early psycholinguistic research, all assume that the interpretation of figurative language requires special cognitive processes (e.g., Grice, 1975, 1978) such as an "idiom mode of processing" (Bobrow \& Bell, 1973). Hence, one of the principal aims of classical linguistics has been the formulation of distinguishing criteria for figurative language. The most important of these are "semantic fixedness" and "syntactic anomaly", which have been found to be closely correlated (Gibbs \& Nayak, 1989). The degrees of semantic fixedness and syntactic anomaly may differ remarkably between phrases which seem at first glance to belong to the same common class. For example, the transformational possibilities open to the German idiomatic phrase "Ich fresse einen Besen" (literal translation (L): I eat a broom; figurative translation (F): "I'll eat my hat") are highly restricted, in that it (a) requires a conditional clause (e.g., "Ich fresse einen Besen, wenn diese Mannschaft gewinnt”; F: "I'll eat my hat if this team wins"), (b) cannot be shifted into the perfect tense, and (c) cannot be expanded by attributes. In contrast, the idiomatic phrase "Er bricht einen Streit vom Zaun" (L: He breaks a quarrel from the fence; F: "He picks a quarrel") is not limited by any of the constraints listed. Hence, newer linguistic research on figurative language assumes a continuum rather than a clear-cut distinction between the "figurative" and "literal" poles (for German see Burger, 2003, 2004; Schindler, 1997; for English see Cacciari \& Glucksberg, 1994; Gibbs, 2002). Analogously, more recent psycholinguistic research generally agrees that figurative language does not require special cognitive efforts or processes (Gibbs, 1994, 2002; Swinney \& Cutler, 1979; for a review see Titone \& Connine, 1999). However, there is an ongoing debate on how these processes might operate and, in particular, how idioms are stored in the mental lexicon.

Models differ on the question of whether the meaning of an idiomatic phrase is stored separately from the meaning of its individual parts and on how the idiomatic 
meaning is assembled. For example, "noncompositional" approaches suggest that the whole idiomatic meaning of a fixed phrase is stored as a distinct entry in the mental lexicon, like the representation of a long word. The process by which the idiomatic meaning is retrieved is thereby assumed to be independent from the computation of the literal meaning (Gibbs, 1980; Swinney \& Cutler, 1979).

In contrast, "compositional" approaches hold that the meaning of an idiomatic phrase is not stored as a separate semantic unit in the mental lexicon, but is assembled on the fly from the meanings of its individual parts (Gibbs, Nayak, \& Cutting, 1989). Such a compositional analysis does not necessarily include an analysis of the literal meanings of each part. Rather, underlying metaphorical concepts are assumed to play an important role in the understanding, storage and processing of idioms (Gibbs, 1992; Gibbs \& O'Brien, 1990; Gibbs, Bogdanovich, Sykes, \& Barr, 1997).

The probably most influential instance of the compositional model has been the "Configuration Hypothesis" of Cacciari and Tabossi (1988), suggesting that idioms are recognized as special word configurations (hence the name "Configuration Hypothesis"). Using Italian sentence material, for an idiomatic sentence, such as "The tennis player was in seventh heaven," lexical decisions about an association with the idiomatic meaning (e.g., happy) were compared to those about an association with the literal meaning of the last word (e.g., saint) and to those about an unrelated word (e.g., umbrella). Furthermore, the degree of the predictability of idioms was varied, and targets were presented either immediately after the sentence prime or with a delay. When there was no bias in the sentence context to suggest an idiom, idiomatic strings were initially processed only literally, and the idiomatic interpretation required a time delay of $300 \mathrm{~ms}$ to be activated. In contrast, when the sentence context predicted an idiom, by the time the last word of a sentence had been reached, only the associations with the idiomatic meaning remained activated. Cacciari and Tabossi concluded that the same processes are involved in assembling both literal and figurative meaning. Idiomatic phrases are initially processed literally until the "key" of an idiom, that is, the specific word configuration associated with the meaning of the idiom, is recognized. After this identification point, the idiom is processed according to its figurative meaning. Hence, the point at which the "key" occurs in a sentence determines which type of meaning is going to be activated. If the "key" does not occur until the end of a sentence, both the literal and the figurative meanings will be activated. If, however, the "key" occurs early in the sentence, the idiomatic meaning alone will remain activated by the end of the sentence.

Unlike Cacciari and Tabossi (1988), who focused on the processing of nouns in idiomatic configurations, our main interest was to explore the processing of verbs in idiomatic configurations, and in particular whether verbs are processed differently in figurative as compared to literal word configurations. The verb is the structural core of the sentence in every syntactic theory and plays a special role in the 
expression of sentence semantics as well. Verb phrases, like other linguistic expressions, are located on a continuum with respect to both syntactic anomaly and semantic fixedness (for German see Ágel, 2004; Burger, 2003). Regarding syntactic anomaly, verb phrases range from completely fixed phrases that do not allow any syntactic modification, such as the idiom "kick the bucket," to those syntactic constructions that are restricted only by the frequency of occurrence. For example, the verb phrase "drink wine" can undergo any syntactic transformation, though the active sentence "I drink wine" is more common than the passive sentence "wine is drunken by me."

Also with regard to semantic fixedness, verb phrases range from absolutely nondecomposable to completely decomposable phrases. In the phrase "drink wine" the verb can take any liquid as complement, such as "drink water" or "drink coconut milk," whereas "kick the bucket" means "die" without any reference to buckets or other containers. Nevertheless, Hamblin and Gibbs (1999) showed that the meaning of the verb in idiomatic phrases may influence the meaning of the idiom. For example, when the verb kick in "kick the bucket" was replaced by a verb that expressed the fast and sudden action, such as punt, this substitution was rated as better preserving the meaning of the idiom than a verb that did not represent the inherent meaning of the verb, such as nudge. That is, the verb-inherent action was transferred to the meaning of the whole idiomatic phrase.

In this study, we explored how the meaning of verbs is processed and therefore examined verbs from two endpoints of the continuum with respect to syntactic anomaly and semantic fixedness: verbs in sentences with literal meaning and verbs in idiomatic phrases.

Given that literal and figurative meanings do not represent a dichotomy but rather a continuum, as is the case with syntactic and semantic fixedness (Gibbs, 2002), we used the following clear-cut distinction between literal and figurative meaning for the sentence material of the present study. We defined a "fully idiomatic phrase" as a verb phrase (a) in which both the verb and its complements are used in a nonliteral way to produce an overall idiomatic interpretation, (b) that shows some kind of morphosyntactic anomaly, and (c) whose idiomatic meaning is lexicalized. Consider the sentence "Mir ist ein Stein vom Herzen gefallen" (word-for-word (W): "to me is a stone from heart fallen"; L: A stone fell off my heart; F: "It took a load off my mind"). First, neither does the verb gefallen refer to the action of falling, nor do the complements Stein or Herzen refer to a rock or a body organ, respectively. Second, the prepositional phrase vom Herzen exhibits transformational defectivity, since it may not be expanded by an adjective or a relative clause. Finally, the phrase "jemandem fällt ein Stein vom Herzen" (F: "to take the load off someone's mind") is a lexical entry in dictionaries of German (e.g., Duden, Redewendungen, 2002).

In contrast, we defined a phrase as literal, if the meaning of the verb designated an action or event, and if the verb phrase lacked the properties (a-c). For 
example, in the sentence "Er ist beim Klettern vom Baum gefallen" (W: "he is while climbing from the tree fallen"; L: He fell out of the tree while climbing), both the verb and the prepositional phrases are used in a literal way, the sentence can undergo all sorts of syntactic transformations and, finally, no dictionary of German lists a verb phrase like "beim Klettern vom Baum fallen" (L: fall out of the tree while climbing).

The aim of the present study was to examine whether verbs in literal phrases activate different meanings than do verbs in idiomatic phrases. For this purpose, we were particularly interested in the use of German verbs. First, up to now there are no online studies on the processing of German verbs in idiomatic sentences, and second, the German sentence structure especially suits the study of semantic associations with the verb. The German perfect tense provides the opportunity to place the verb, that is, the past participle which bears the lexical meaning of the analytic expression of the German perfect tense at the very end of the sentence. ${ }^{1}$ Different semantic associations with the verb can thus be tested immediately after the verb has been presented.

In order to contrast the processing of a verb in figurative word configurations with that of literal word configurations, each idiomatic sentence was paired with a literal sentence that comprised the same verb. A cloze probability of roughly $90 \%$ (as assessed in a sentence-completion task) ensured that the verb in sentence-final position was highly predictable. That is, idiomatic and literal sentences in our experiment were similar in their degree of predictability, though - by definition-they remarkably differed with respect to their degree of semantic fixedness and syntactic anomaly. It was thus established that in both types of sentences the phrasal meaning was processed and the word configuration was rendered as either figurative or literal before the last word of a sentence.

We used a sentence-priming experiment similar to the one employed in the study of Cacciari and Tabossi (1988). Participants read a sentence, which included either a verb embedded in a sentence with figurative meaning, such as "Sie hat ihm gründlich den Kopf gewaschen" (W: "she has him thoroughly the head washed"; L: She thoroughly washed his head; F: "She gave him a piece of her mind") or a corresponding literal control sentence, in which the same verb took a literal meaning, as in "Er hat beim Duschen die Haare gewaschen" (W: "he has while showering the hair washed"; L: He washed his hair while showering). Participants made lexical decisions about words associated with the whole figurative meaning, such as Standpauke (telling-off), about associations with the literal meaning of the verb, such as Kleidung (clothes), and about completely unrelated words, such as Wappentier (heraldic animal) and Freizeit (leisure time).

Moreover, we minimized the influence of some confounding variables that were not controlled in Cacciari and Tabossi (1988): (a) the number of words in a

\footnotetext{
${ }^{1}$ Exceptions, that is, the so-called "right-dislocation" are possible if the sentence is marked.
} 
sentence was alike, that is, each sentence comprised seven words, whereas they took between nine and nineteen words in the study of Cacciari and Tabossi; (b) in the present study, the position of the verb was always sentence-final, while the critical prime word was placed between zero and six words before the sentence-final position in Cacciari and Tabossi; (c) in the present study, the word class of the target was always a noun, while the study of Cacciari and Tabossi included nouns, adjectives, adverbs, and verbs; (d) literal associations are usually concrete words that possess fewer letters and are of higher frequency than associations with the figurative meaning of an idiom. Hence, instead of having a single baseline, we matched each association with an unrelated noun on frequency, number of letters, and number of syllables. Finally, to provide a strong basis for the generalization of our findings, we examined 59 different idiomatic phrases and their corresponding literal phrases, while Cacciari and Tabossi tested between nine and twelve idiomatic phrases (without testing literal phrases).

In accordance with the methodology of priming studies (for a review see Neely, 1991), we defined the activation of an associated noun as reaction time gain relative to its matched unrelated noun. Examples of figurative and literal sentences and their corresponding associations are given in Table 1.

The experimental conditions of the present study ensured that the phrasal meaning was processed before the presentation of the literal or figurative associations: First, we used highly predictable idiomatic sentences, so that-according to the "Configuration Hypothesis" (Cacciari \& Tabossi, 1988) - the "key" for the figurative phrases should occur early in the sentence, at any rate before the verb. Second, we presented the target association $500 \mathrm{~ms}$ after the presentation of the verb in sentence-final position, so that-according to the "Configuration Hypothesis"- only the relevant (literal or figurative) phrasal meaning should still be activated. Under these conditions, the "Configuration Hypothesis" predicts that in figurative phrases, only associations with the figurative meaning of the sentence should be activated, but not words associated with the literal meaning of the verb. Although Cacciari and Tabossi did not examine the processing of literal sentences, the same logic should apply here as well: Given that the literal phrasal meaning is highly predictable, no idiom "key" can occur in the sentence, and only associations with the literal verb meaning should be activated.

If, however, our assumption holds that the verb is the structural center of the phrase, the literal meaning of the verb should be activated regardless of whether a specific word configuration is literal or figurative. Hence, we predict that in idiomatic phrases, associations both with the literal meaning of the verb and with the figurative meaning of the phrase will be activated.

We further asked whether the lexical entry of a verb entails only its literal meaning or also the meaning of those figurative expressions that comprise the verb. That is, if the lexical entry of the verb fallen (to fall) relates solely to the literal meaning of falling — to drop or come down freely under the influence of gravity—only the 


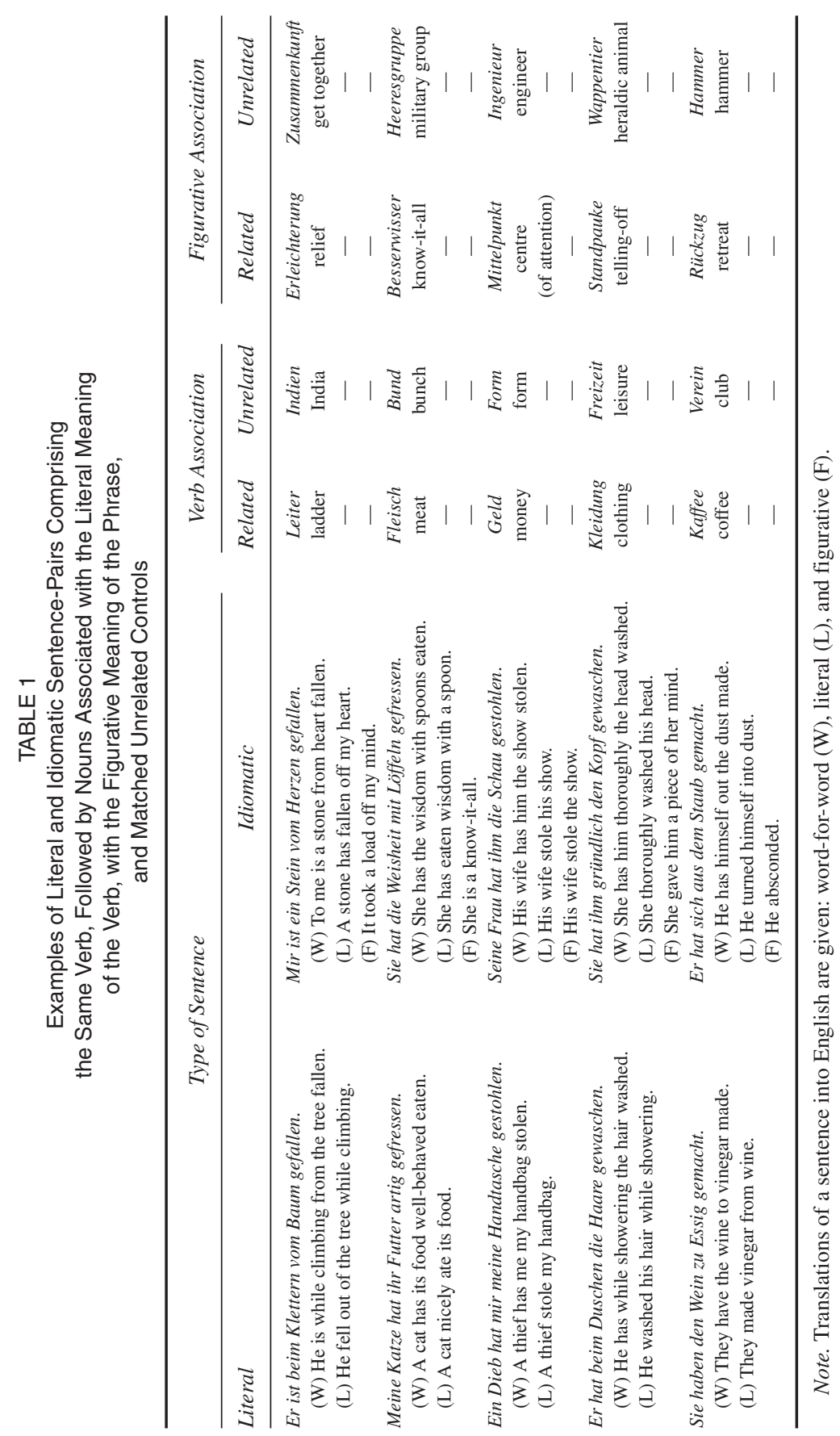


association with the literal meaning of the verb should be activated in literal sentences. If, however, the lexical entry of fallen relates also to its more abstract or metaphoric meanings, as in "stocks fell sharply," or as in idiomatic expressions such as "jemandem fällt ein Stein vom Herzen" (F: "to take the load off someone's mind") or "jemandem in den Rücken fallen" (L: to fall into someone's back; F: "to stab someone in the back"), some activation of the figurative meaning besides the literal meaning may occur even in literal sentences.

\section{METHOD}

\section{Participants}

Fifty-one Marburg university students participated in the experiment for course credit or payment. A questionnaire assessed that they were monolingual native speakers of German, were not dyslexic, and had normal or corrected-to-normal vision.

\section{Material}

A total of 456 sentences were used in the experiment, 118 experimental sentences and 338 filler sentences. All sentences were chosen from the pool of sentences tested in the sentence-completion experiment described below.

\section{Sentence Completion Task}

About 1135 sentences in literal or figurative meaning were constructed and each consisted of seven words and was cast in the perfect tense. In German, the perfect tense is expressed by an auxiliary from the verbs sein (to be) or haben (to have) in the second place in a declarative sentence and the past participle form of a verb in sentence-final position. Sentences were semantically and syntactically structured in such a way as to prime the verb in sentence-final position. About 420 different verbs were used and hence the same verb appeared in several different sentences. All verbs had participles, which were built by adding the prefix $g e$ - and the suffix - $t$ or -en to the stem. For the completion task, the last word of a sentence was omitted and replaced with the participle prefix $g e$ - and a blank. For example, the intended sentence "Mir ist ein Stein vom Herzen gefallen" (W: "to me is a stone from heart fallen"; L: A stone fell off my heart; F: "It took a load off my mind"), was presented as "Mir ist ein Stein vom Herzen ge

Six lists were created from the sentence pool, each including about 189 sentences. In an experimental session, one list was shown, and lists were rotated from one session to the next. The online sentence-completion experiment was assem- 
bled using the software provided by "Language Experiments Portal" (Keller, Corley, Corley, Konieczny, \& Todirascu, 1998). ${ }^{2}$

Each sentence was completed by between 25 and 32 monolingual native speakers of German (altogether 136 participants who did not participate in the sentence-priming experiment). For each sentence, the number of sentence completions with a specific verb were counted (completions with spelling mistakes were counted as if spelled correctly; "Don't know" answers were included in the count). For example, 25 of the 25 participants who saw the sentence "Mir ist ein Stein vom Herzen ge " completed it with fallen, thus providing the participle gefallen (fallen).

\section{Experimental Sentences}

From this pool, 59 idiomatic and 59 literal sentences were selected for the sentence-priming experiment. They were chosen in such a way that idiomatic and literal sentences comprising the same verb were closely matched on completion rates. For example, the completion rate of the idiomatic phrase "Mir ist ein Stein vom Herzen gefallen" (W: "to me is a stone from heart fallen"; L: A stone fell off my heart; F: "It took a load off my mind") was 100\%, and that of the corresponding literal sentence "Er ist beim Klettern vom Baum gefallen" (W: "he is while climbing from the tree fallen"; L: He fell out of the tree while climbing) was $96 \%$.

On average, sentences in the idiomatic condition were completed with verbs that produced the idiomatic meaning in $91 \%$ of the cases (range 52-100\%). The corresponding literal control sentences were completed with the literal verb meaning in $87 \%$ of the cases (range $56-100 \%$ ).

We defined a "fully idiomatic phrase" as a verb phrase (a) where both the verb and its complement are used in a nonliteral way to produce an overall idiomatic interpretation, (b) that shows some kind of morphosyntactic anomaly, and (c) whose idiomatic meaning is lexicalized (see above). In the light of these three properties, the idiomaticity of the phrases selected was agreed upon by three independent judges and further verified by reference to an idiomatic phrase dictionary (Duden, Redewendungen, 2002).

\section{Association Material}

Two types of associations were selected for each experimental sentence pair: verb associations $(\mathrm{V})$, that is, nouns related to the literal meaning of the verb, and figurative associations $(\mathrm{F})$, that is, nouns related to the idiomatic meaning of the phrase. It was taken care of that a verb association was not only unassociated with

\footnotetext{
${ }^{2}$ The experiment was advertised through the "Language Experiments Portal" at URL http:// www.language-experiments.org/.
} 
the figurative phrasal meaning but that it was also unassociated with any of the content words of the figurative phrase.

The strength of the associations was assessed in a pre-test. For this purpose, the literal verb and the figurative expression of each sentence pair were transferred into the citation form and allocated to two lists via Latin square. Thus, a list contained either the literal verb or the figurative expression of the same verb. Each (literal or figurative) expression was presented with three associated nouns. For example, the verb fallen (to fall) was presented with the nouns Leiter (ladder), Grube (pit), and Boden (ground). The idiomatic expression "jemandem fällt ein Stein vom Herzen" (F: "to take the load off someone's mind”) was presented with the nouns Entspannung (relaxation), Erleichterung (relief), and Freude (joy). Forty-four participants (who participated neither in the sentence-completion task nor in the sentence-priming experiment) rated which of the three nouns was most (1), medium (2), or least (3) associated with the expression. Those associations with the lowest rating were selected as idiomatic and literal associations (mean ratings were 1.43 and 1.48 , respectively).

Since verb and figurative associations differ on distributional variables, that is, nouns associated with the literal meaning of the verb comprise fewer letters and syllables and are of higher frequency than nouns associated with the figurative meaning of a phrase, responses for verb associations cannot be directly compared to those for figurative associations. Hence, for each (verb and figurative) association, a word was selected that was unrelated to both the literal verb meaning and the figurative meaning, the verb control (VC) or figurative control (FC), respectively. This unrelated word was a noun and thus belonged to the same word category as the association it was matched to. Most important, it was matched to the related association on lemma frequency, number of letters, and number of syllables. According to frequency counts from the CELEX database (Baayen, Piepenbrock, \& Van Rijn, 1993), figurative associations had a mean lemma frequency of 31 occurrences per million words (range 0-1041), their unrelated controls had a mean frequency of 31 per million (range 0-987); verb associations had a frequency of 65 per million (range 0-475), and their unrelated controls had a mean lemma frequency of 70 per million (range 0-465).

\section{Filler Material}

A total of 338 sentences were selected as filler sentences from the sentence pool described above. All filler sentences comprised verbs that appeared only once in the filler set and differed from those in the experimental set.

Hundred and ten filler sentences were followed by an unassociated noun. Corresponding to the nouns of the association material described above, half of the filler nouns consisted of three syllables, the other half of one or two syllables. All nouns besides two appeared only once in the whole material set. 
The remaining 228 filler sentences, of these 35 with an idiomatic meaning, were followed by a pseudoword. Pseudowords were constructed by exchanging one or two letters of an existing noun, while preserving the phonotactic constraints of the German language.

\section{Apparatus}

Stimuli were presented on a 17 " monitor, connected to an IBM-compatible Pentium III personal computer. Response latencies were recorded from the left and right "control" keyboard keys.

\section{Procedure}

Four lists were constructed; each included both the literal and the figurative version of all experimental sentence pairs and all filler sentences (in total 456 sentences). The four different association types of a an experimental sentence pair were rotated over the four lists by Latin square in such a way that a list contained either the figurative association (FA) together with the unrelated verb control (VC) or it contained the verb association (VA) together with the unrelated figurative control (FC). For example, in the first list, the idiomatic phrase "Mir ist ein Stein vom Herzen gefallen" (F: "It took a load off my mind") preceded the figurative association Erleichterung (relief), and the literal sentence "Er ist beim Klettern vom Baum gefallen" (L: He fell out of the tree while climbing) preceded the verb control Indien (India), and vice versa in the second list. In the third list, the idiomatic phrase preceded the figurative control Zusammenkunft (get together), and the literal phrase preceded the verb association Leiter (ladder), and vice versa in the fourth list.

Participants were randomly assigned to a list. Each list was further subdivided into six blocks of 76 trials. The ordering of the sentences within a block was randomized for each participant. Participants were tested individually in a dimly lit room and were seated at a viewing distance of about $60 \mathrm{~cm}$ from the screen. Participants ran through 11 practice trials before the experimental blocks.

Each trial started with a fixation point in the center of the screen for $500 \mathrm{~ms}$, followed by the seven words of a sentence, each presented for $500 \mathrm{~ms}$ in the center of the screen. Five hundred $\mathrm{ms}$ after the last word of a sentence (SOA $=500 \mathrm{~ms}$ ) the target item appeared in green letters $0.9 \mathrm{~cm}$ above the center of the screen and remained there until the participant's response. Words were presented in 18-point Sans Serif font.

Participants made lexical decisions to the targets, as fast and as accurately as possible. "Word" responses were made by pressing one of the "control" keyboard keys with the index finger of the dominant hand, "pseudoword" responses were made with the subordinate hand. During the practice trials, participants received 
automatic feedback for all responses, during the experiment, only for incorrect responses; they could self-monitor the length of the breaks between blocks. The experiment lasted for about 50 minutes.

\section{RESULTS}

All analyses were performed on latency and accuracy data with participants $\left(F_{1}\right)$ and verbs $\left(F_{2}\right)$ treated as random variables. The data of two participants with more than $15 \%$ errors on word responses were removed, so that 49 participants were included in the data analyses (mean error rate was 3.3\%); the data of two verbs, that is, of two sentence pairs were removed (since more than $50 \%$ of the participants produced incorrect responses to one of the control words), leaving a total of 57 sentence pairs in the data analyses. Mean response latencies were calculated for correct responses, and reaction times (RTs) exceeding 2.5 standard deviations from a participant's mean were excluded. RT and error means are given in Table 2.

We intended to explore whether verbs in idiomatic and literal phrases activate different associations. The amount of activation was calculated separately for each type of phrase (and participant) by subtracting the mean of the associated condition from that of its matched unrelated control condition: verb controls (VC) minus verb associations (V) for verb activation (VA), and figurative controls (FC) minus figurative associations (F) for figurative activation (FA). Figure 1 depicts these activation effects.

These activation effects were entered in $2 \times 2$ analyses of variance (ANOVA) with repeated measures factors phrase (literal/idiomatic) and association (verb/figurative). Since there were no significant effects with the accuracy data, in the following the effects of response latency are described.

TABLE 2

Lexical Decision Latencies and Accuracies for Verb Associations, Figurative Associations, and Matched Unrelated Controls Presented after Literal and Idiomatic Sentences

\begin{tabular}{|c|c|c|c|c|c|c|c|c|}
\hline \multirow{3}{*}{$\begin{array}{l}\text { Type of } \\
\text { Phrase }\end{array}$} & \multicolumn{4}{|c|}{ Verb Associations } & \multicolumn{4}{|c|}{ Figurative Associations } \\
\hline & \multicolumn{2}{|c|}{ Related } & \multicolumn{2}{|c|}{ Unrelated } & \multicolumn{2}{|c|}{ Related } & \multicolumn{2}{|c|}{ Unrelated } \\
\hline & $R T$ & Error & $R T$ & Error & $R T$ & Error & $R T$ & Error \\
\hline Literal & $572(72)$ & 2.0 & $611(75)$ & 5.1 & $646(90)$ & 2.0 & $661(111)$ & 5.9 \\
\hline Idiomatic & $569(68)$ & 1.9 & $596(76)$ & 3.5 & $622(89)$ & 1.6 & $654(104)$ & 4.6 \\
\hline
\end{tabular}

Note. Mean RTs in milliseconds (SD in parentheses) and error means. 


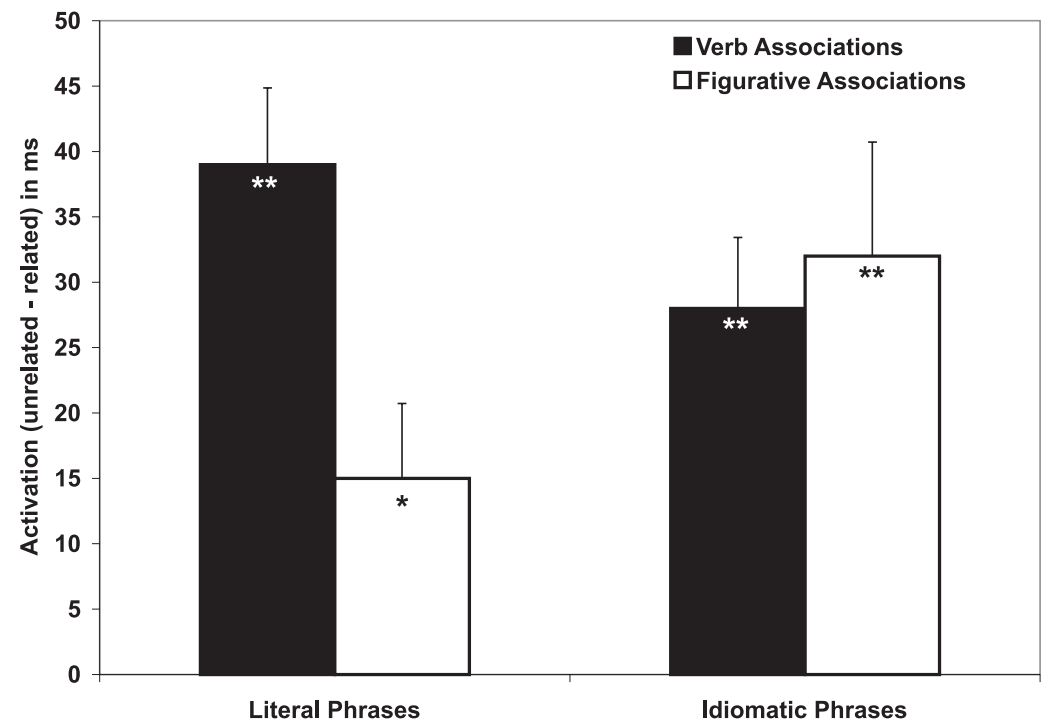

FIGURE 1 Activation (unrelated minus related) for nouns associated with the literal meaning of the verb or with the figurative meaning of the phrase presented after literal or idiomatic phrases. ${ }^{*} p<.05$ indicates significance level in the participants analysis; $* * p<.05$ indicates significance level in both participants and items analyses.

The main effect of phrase was not significant $\left(F_{1}\right.$ and $\left.F_{2}<1\right)$, indicating that nouns following literal phrases $(27 \mathrm{~ms}$ ) were activated to the same extent as those following idiomatic phrases $(30 \mathrm{~ms})$. Also the main effect of association was not significant, $F_{1}(1,48)=2.64, p=.1105 ; F_{2}(1,56)=1.22, p=.2735$, confirming that verb associations ( $34 \mathrm{~ms}$ ) were activated to the same degree as were figurative associations $(24 \mathrm{~ms})$. The interaction between phrase and association was marginally significant in the participants analysis, $F_{1}(1,48)=3.77, p=.0580$, and significant in the items analysis, $F_{2}(1,56)=4.64, p=.0356$.

In order to examine this interaction more closely, the effects of verb and figurative association were analyzed separately for literal and idiomatic phrases. As expected, in the literal-phrase condition, the main effect of association was significant, $F_{1}(1,48)=8.01, p=.0068 ; F_{2}(1,56)=4.01, p=.0502$. Verb associations $(39 \mathrm{~ms})$ were more strongly activated than were figurative associations (15 $\mathrm{ms})$. By way of contrast, in the idiomatic-phrase condition, the main effect of association was not significant $\left(F_{1}\right.$ and $\left.F_{2}<1\right)$, indicating that the activation of verb associations $(28 \mathrm{~ms})$ was as strong as the activation of figurative associations (32 ms). 


\section{DISCUSSION}

The experiment investigated how verbs in figurative language are stored and processed in the mental lexicon, more specifically, whether verbs in idiomatic phrases activate different types of associations than do verbs in literal sentences. Associations with the figurative meaning of a phrase were contrasted with associations with the same verb in a literal sense and with unassociated nouns. The processing of literal and idiomatic sentences should yield different patterns of meaning activation, nevertheless, we expected the literal meaning of the verb to be activated in both types of sentences.

Indeed, our results showed that in literal sentences, associations with the literal meaning of the verb were more strongly activated than were associations with the figurative meaning. Most importantly, in idiomatic sentences associations with the literal meaning of the verb were activated to the same degree as were associations with the figurative meaning. In this respect our results are straightforward: the literal meaning of the verb is always activated, in both literal and in idiomatic sentences.

These findings contradict the predictions of the "Configuration Hypothesis." and in particular the implementation of an idiom "key" (Cacciari \& Tabossi, 1988). In highly predictable idiomatic sentences, the "key" or point at which the idiomatic word configuration is recognized occurs early on. The recognition of the idiom "key" is assumed to make the processing of the literal meaning superfluous to the subsequent sentence recognition task, so that the literal meaning should not be further processed, in contrast to the figurative meaning of the word configuration. Therefore, Cacciari and Tabossi assume that by the end of the sentence only associations with the figurative meaning of an idiom should be activated.

This definition of an idiom "key" was based on what Cacciari and Tabossi considered highly idiomatically-biased sentences, namely sentences that had an idiomatic cloze probability of $45 \%$. The sentence material and design of our study should produce even stronger evidence in favor of the "Configuration Hypothesis": First, a sentence-completion task assessed that the verbs in sentence-final position were highly predictable, that is, our idiomatic sentences had an average cloze probability of $91 \%$ (compare with the cloze probability of $45 \%$ in Cacciari \& Tabossi). This assured that the word configurations were recognized as figurative before the verb was presented. Furthermore, to ensure that the idiomatic meaning was comprehended well before the presentation of the targets, target associations were delayed $500 \mathrm{~ms}$ after the presentation of the verb. Nevertheless, we found that associations with the literal meaning of the verbs were strongly activated, and what's more, they were activated to the same degree as were the associations with the figurative meaning of the sentences.

This activation of literal meaning may be specific to verbs. In terms of syntax, the verb is the structural center of the sentence because it opens the positions of the complements, namely those elements which are syntactically obligatory. These complements, in turn, are dependent on the subcategorization properties of the verb and are thus predictable as soon as the verb has been processed. In our experi- 
mental setting, where the subcategorizing verb occupies the sentence-final position, the direction of predictability is reversed: The number and type of complements that occur in the sentence constrain the choice of possible verbs in the last position, so that the verb is partially processed even before it is realized.

The same holds true from a semantic perspective. Concerning idioms, Hamblin and Gibbs (1999) found that the verb-inherent action affects the meaning of the whole phrase. Consider the German idiom "Damit hat er Öl ins Feuer gegossen" (L: He poured oil in the fire with that; F: He added fuel to the fire with that). The preposition $i n(s)$ is a German preposition that can govern both the dative case for locations (indicating the semantic feature [+static]) and the accusative case for directions (indicating the feature [-static]; Gansel, 1992). Because an accusative case is assigned in the above example, the semantic feature [-static] of the participle form gegossen (poured) can be anticipated. Therefore, even from a semantic point of view, certain verb properties are processed before the verb itself is realized.

As a consequence of the syntactic and semantic processing properties of verbs, we question Cacciari and Tabossi's (1988) notion of an idiomatic "key" and its implication that the literal meaning is not processed any longer subsequent to the recognition of an idiomatic word configuration. We agree that there is a certain point at which a word configuration is recognized as being idiomatic. However, our findings indicate that this point in time does not determine whether the literal meaning of verbs is activated or not. Rather, the processing of the literal meaning of the verb is independent of the point at which the idiom is recognized.

Even though our results show that the literal verb meaning is inevitably activated, we do not assume that the processing of the literal verb meanings is a precondition for the processing of the figurative meaning. Such an assumption would predict longer response latencies for the processing of figurative meaning as compared to that of literal meaning. However, a comparison of the baseline conditions (i.e. the unrelated conditions) in our study shows that the phrasal meaning of the idiomatic sentences was processed as fast as or even faster than the phrasal meaning of the literal sentences. ${ }^{3}$ We thus agree with Gibbs (2002) that figurative mean-

\footnotetext{
${ }^{3}$ In order to examine whether the phrasal meaning of literal sentences is processed differently than the phrasal meaning of idiomatic sentences, literal and idiomatic sentences were compared by means of their baseline conditions (i.e. the unrelated conditions). The one-way ANOVA with repeated measures factor phrase (literal/idiomatic) was significant in the participants analysis, $F_{1}(1,48)=6.18, p=.0164$, but not in the items analysis, $F_{2}(1,56)=2.04, p=.1588$, indicating that responses for unrelated nouns were slightly faster following idiomatic sentences $(625 \mathrm{~ms})$ than after literal sentences $(636 \mathrm{~ms})$.

This effect was further examined separately for unrelated nouns of verb associations and for those of figurative associations, since unrelated nouns matched to verb associations were of higher frequency and fewer letters than those matched to figurative associations. Regarding the baseline of verb associations, the effect was significant in the participants analysis, $F_{1}(1,48)=6.59, p=.0135$, but not in the items analysis, $F_{2}(1,56)=2.35, p=.1306$, indicating that responses for unrelated nouns were slightly faster following idiomatic sentences $(596 \mathrm{~ms})$ than after literal sentences $(611 \mathrm{~ms})$. However, regarding the baseline of figurative associations, the effect was not significant $\left(F_{1}\right.$ and $\left.F_{2}<1\right)$, confirming that the phrasal meaning of literal sentences $(661 \mathrm{~ms})$ was processed equally fast as that of idiomatic sentences $(654 \mathrm{~ms})$.
} 
ings are not second-level interpretations that necessitate complete literal interpretations of the utterances on the first level. Rather, our results demonstrate that figurative interpretations do not block the activation of literal associations even in contexts in which they are completely redundant.

Our findings are more compatible with recent hybrid models of idiom processing (Caillies \& Butcher, 2007; Cutting \& Bock, 1997; Sprenger, Levelt, \& Kempen, 2006) that account for the "paradox" of idioms being both unitary and compositional: On the one hand, the individual words that constitute an idiom are separately addressable processing units, while on the other hand, they receive a distinct representation. For example, the unitary representation of a "superlemma" engages morphosyntactic constraints on the idiomatic configuration and discriminates idiomatic from literal word configurations (Sprenger et al., 2006). Semantic constraints have been suggested to differentiate between decomposable and nondecomposable idioms. While the figurative meaning of a decomposable idiom possesses rich structural network connections with its component words, nondecomposable idioms lack such connections (Caillies \& Butcher, 2007). These hybrid models thus assume different representations to distinguish between semantically decomposable and nondecomposable idioms (e.g., Caillies \& Butcher, 2007) or idiomatic and literal word configurations (Cutting \& Block, 1997; Sprenger et al., 2006).

In contrast, we propose a model that comprises the same representations and processes for both idiomatic and literal configurations. Since our idiomatic configurations were mostly nondecomposable according to the definition of Caillies and Butcher (2007), our model may generalize to the processing of composable as well as nondecomposable idioms. Figure 2 exemplifies the processing of the idiomatic sentence "Mir ist ein Stein vom Herzen gefallen" (F: "It took a load off my mind"), the literal sentence "Er ist beim Klettern vom Baum gefallen" (L: He fell out of the tree while climbing), and the corresponding associations with either the literal meaning of the verb, Leiter (ladder), or the figurative meaning of the phrase, Erleichterung (relief).

Utterances in orthographic form (as is the case in our experiments) or phonological form are morphologically decomposed. The single morpheme is accessed, and its associated mental concept is activated (Smolka, Zwitserlood, \& Rösler, in press). For example, as soon as the participle gefallen (fallen) is encountered, it is decomposed, so that the morpheme fall is accessed, which activates the meaning fallen (to fall) at the concept level (for the sake of clarity, concepts are represented by English words in Figure 2). The frequency of a particular morpheme determines the strength of meaning activation at the concept level. Semantic spreading activation at the concept level will further activate closely related associations, such as the concept Leiter (ladder). Indeed, our findings have shown that the literal meaning of the verb is activated regardless of whether the verb is part of a literal or an idiomatic sentence, and at what point in time the word configuration is recognized as literal or figurative. 


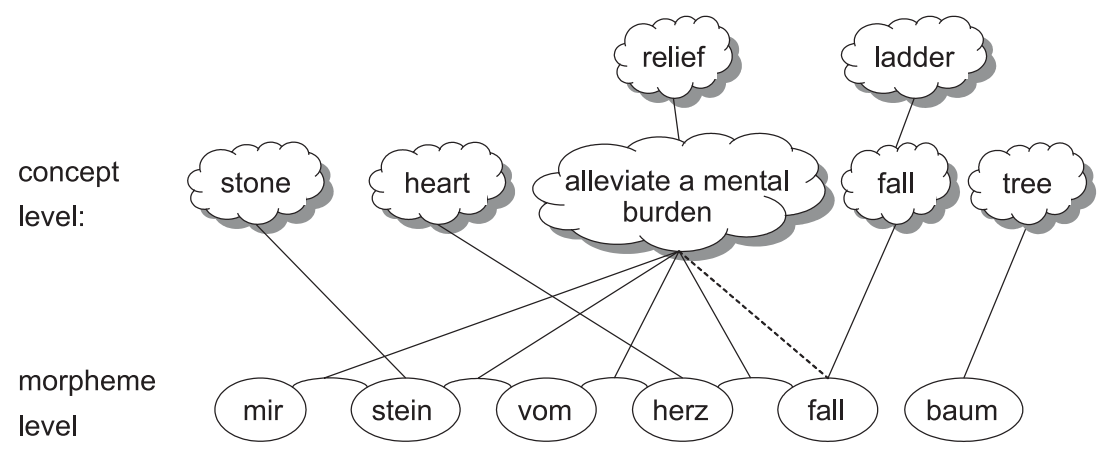

input

Mir ist ein Stein vom Herzen gefallen.

level

$W$ : to me is a stone from the heart fallen

Er ist beim Klettern vom Baum gefallen.

$\mathrm{W}$ : he is while climbing from the tree fallen

$L$ : A stone has fallen off my heart.

$\mathrm{L}$ : He fell out of the tree while climbing

F: "It took a load off my mind."

FIGURE 2 Model of idiom recognition.

In addition to the activation of single morphemes and their concepts, also particular combinations of morphemes activate each other and their joint concept. These combinations of morphemes may not only represent morphologically complex words, such as inflected or derived forms, but also collocations, which are non-idiomatic word configurations that display some moderate syntactic as well as semantic fixedness, or idiomatic combinations (as is the case in this experiment). For example, the combination of the morphemes mir, stein, vom, herz, fall, will activate the common concept that expresses the idiomatic meaning "to alleviate a mental burden." At the concept level, the meaning of this concept will further activate the closely related concept Erleichterung (relief), as our results have shown. The frequency of a particular morpheme combination determines how strongly the common concept will be activated. This further explains why a literal sentence like "Er ist beim Klettern vom Baum gefallen" may not only activate the association with the literal meaning of the verb fallen but also-at least to some degree- the concept of an idiom that comprises the same verb. The frequent co-occurrence of the morpheme fall and the morphemes stein, vom, and herz, will give rise to the activation of the idiomatic concept, even if fall occurs in a non-idiomatic sentence (as represented by the dotted line in Figure 2). In this respect, the lexical entry of a verb may entail not only its literal meaning, but also the meaning of those abstract and figurative expressions that comprise the verb.

We have argued that verb phrases are located on a continuum with regard to syntactic as well as semantic fixedness. According to recent valency theory (Ágel, 2004), relatively fixed expressions do not represent an exception but rather the default of linguistic structure. The model we present here is a unitary system for the 
processing of literal and figurative language: Morpheme combinations, which may form single words and up to complex combinations such as idioms, activate their corresponding joint concept. The meaning activation at the concept level is determined by the frequency of a single morpheme as well as by the frequency of the particular morpheme combination. Since each morpheme will always activate its closely related concept, literal meaning associations will be available regardless of the meaning of the whole phrase.

\section{ACKNOWLEDGMENTS}

This research was supported by grant For 254/2 of the German Research Foundation (DFG) to Frank Rösler.

We would like to thank Mark Pennay for his editorial help, Sandra Kanfer for the translation of the examples, and Nathalia Weber for running the experiment. We also thank Ray Gibbs and an anonymous reviewer for helpful comments on an earlier version of this paper.

\section{REFERENCES}

Ágel, V. (2004). Phraseologismus als (valenz)syntaktischer Normalfall. In K. Steyer (Ed.), Wortverbindungen - mehr oder weniger fest (pp. 65-86). Berlin/New York: Walter de Gruyter.

Baayen, R., Piepenbrock, R., \& Van Rijn, H. (1993). The CELEX lexical database (on CD-ROM). Philadelphia, PA: Linguistic Data Consortium, University of Pennsylvania.

Bobrow, S., \& Bell, S. (1973). On catching on to idiomatic expressions. Memory and Cognition, 1, 343-346.

Burger, H. (2003). Phraseologie. Eine Einführung am Beispiel des Deutschen (Rev. ed.). Berlin: Erich Schmidt.

Burger, H. (2004). Phraseologie - Kräuter und Rüben? Traditionen und Perspektiven der Forschung. In K. Steyer (Ed.), Wortverbindungen - mehr oder weniger fest (pp. 19-40). Berlin/New York: Walter de Gruyter.

Cacciari, C., \& Glucksberg, S. (1994). Understanding figurative language. In M. Gernsbacher (Ed.), Handbook of psycholinguistics (pp. 447-477). San Diego, CA, US: Academic Press.

Cacciari, C., \& Tabossi, P. (1988). The comprehension of idioms. Journal of Memory and Language, 27, 668-683.

Caillies, S., \& Butcher, K. (2007). Processing of idiomatic expressions: Evidence for a new hybrid vew. Metaphor and Symbol, 2, 79-108.

Cutting, J., \& Bock, K. (1997). That's the way the cookie bounces: syntactic and semantic components of experimentally elicited idiom blends. Memory and Cognition, 25, 57-71.

Duden Redewendungen: Wörterbuch der deutschen Idiomatik (2nd ed.). (2002). Mannheim: Dudenverlag.

Frege, G. (1923). Logische Untersuchungen. Dritter Teil: Gedankengefüge. Beiträge zur Philosophie des deutschen Idealismus, 3, 36-51.

Gansel, C. (1992). Semantik deutscher Verben in kognitionspsychologischer Sicht. Frankfurt am Main: Peter Lang. 
Gibbs, R. W. (1980). Spilling the beans on understanding and memory for idioms in conversation. Memory and Cognition, 8, 149-156.

Gibbs, R. W. (1992). What do idioms really mean? Journal of Memory and Language, 31, 485-506.

Gibbs, R. (1994). Figurative thought and figurative language. In M. Gernsbacher (Ed.), Handbook of psycholinguistics (pp. 411-446). San Diego, CA, US: Academic Press.

Gibbs, R. W. (2002). A new look at literal meanings in understanding what is said and implicated. Journal of Pragmatics, 34, 457-486.

Gibbs, R. W., Bogdanovich, J. M., Sykes, J. R., \& Barr, D. J. (1997). Metaphor in idiom comprehension. Journal of Memory and Language, 37, 141-154.

Gibbs, R. W., Nayak, N. P., \& Cutting, C. (1989). How to kick the bucket and not decompose: Analyzability and idiom processing. Journal of Memory and Language, 28, 576-593.

Gibbs, R. W., \& Nayak, N. P. (1989). Psycholinguistic studies on the syntactic behavior of idioms. Cognitive Psychology, 21, 100-138.

Gibbs, R.W., \& O'Brien, J. E. (1990). Idioms and mental imagery: The metaphorical motivation for idiomatic meaning. Cognition, 36, 35-68.

Grice, H. P. (1975). Logic and conversation. In P. Cole, \& J. Morgan (Eds.), Syntax and semantics, vol. 3: Speech acts (pp. 41-58). New York: Academic.

Grice, H. P. (1978): Further notes on logic and conversation. In P. Cole (Ed.), Syntax and semantics, vol. 9: Pragmatics (pp. 113-127). New York: Academic.

Hamblin, J. L., \& Gibbs, R. W. (1999). Why you can't kick the bucket as you slowly die: Verbs in idiom comprehension. Journal of Psycholinguistic Research, 28, 25-39.

Keller, F., Corley, M., Corley, S., Konieczny, L., \& Todirascu, A. (1998). WebExp: A Java Toolbox for Web-based Psychological Experiments. Technical Report HCRC/TR-99. Human Communication Research Centre, University of Edinburgh. Available from http://www.hcrc.ed.ac.uk/web_exp/.

Neely, J. H. (1991). Semantic priming effects in visual word recognition: A selective review of current findings and theories. In D. Besner, \& G. W. Humphreys (Eds.), Basic processes in reading (pp. 264-336). Hillsdale, NJ: Lawrence Erlbaum Associates.

Schindler, W. (1997). Methodologische Überlegungen zu idiomatischen Wortverbindungen und deren Abgrenzung von anderen phraseologischen Syntagmen. In I. Pohl (Ed.), Methodologische Aspekte der Semantikforschung (pp. 267-282). Frankfurt: Peter Lang.

Smolka, E., Zwitserlood, P., \& Rösler, F. (in press). Stem access in regular and irregular inflection: Evidence from German participles. Journal of Memory and Language.

Sprenger, S., Levelt, W., \& Kempen, G. (2006). Lexical access during the production of idiomatic phrases. Journal of Memory and Language, 54, 161-184.

Swinney, D., \& Cutler, A. (1979). The access and processing of idiomatic expressions. Journal of Verbal Learning and Verbal Behavior, 18, 523-534.

Titone, D. A., \& Connine, C. M. (1999). On the compositional and noncompositional nature of idiomatic expressions. Journal of Pragmatics, 31, 1655-1674. 